\title{
Potential for Improving the Energy Efficiency of Cryogenic Air Separation Unit (ASU) using Binary Heat Recovery Cycles
}

\author{
Mathew Aneke*, Meihong Wang \\ School of Engineering, Faculty of Science and Engineering, University of Hull, HU6 7RX, \\ United Kingdom
}

\begin{abstract}
In this paper, the potential of improving the energy efficiency of a conventional cryogenic air separation unit (ASU) was investigated through modeling and simulation using Aspen Plus ${ }^{\circledR}$ $\mathrm{v}$ 8.1. It is achieved through converting the heat from the compressor effluent to electricity using organic Ranking cycle (ORC). Two different arrangements of combining compressor and waste heat recovery ORC system were compared with the conventional cryogenic ASU which was used as the benchmark. The benchmark is a conventional cryogenic ASU with 3 stages of compression which uses water for intercooling. In the first arrangement the water used as the cooling fluid of the intercooler/after cooler heat exchanger of a conventional cryogenic ASU process was replaced by R134a which also acts as the working fluid for the ORC system (C3WHR) while in the second arrangement, the 3 stages compressor of the conventional process was replaced with a single stage compressor with the same overall pressure ratio as the conventional process and the hot compressor effluent cooled with R134a which also acts as the working fluid of the ORC system (C1WHR).

The simulation results based on a cryogenic ASU capable of processing $100 \mathrm{~kg} / \mathrm{s}$ of atmospheric air at $30{ }^{\circ} \mathrm{C}$ as feedstock show that the specific power consumption for the pure products which was $0.32 \mathrm{kWh} / \mathrm{kg}, 0.37 \mathrm{kWh} / \mathrm{kg}$ and $17.35 \mathrm{kWh} / \mathrm{kg}$ for oxygen, nitrogen and argon respectively for the conventional cryogenic ASU process was reduced by the addition of the waste heat recovery ORC system. The C1WHR reduced the specific power consumption by an average of $0.2 \%$ across the aforementioned pure products while the C3WHR reduced it by an average of $11 \%$. The net power consumption of the conventional cryogenic ASU which was $21826.19 \mathrm{~kW}$ was also found to be reduced by the same percentage.
\end{abstract}

Keywords: Cryogenic Air Separation Unit; Organic Rankine Cycle; Waste Heat Recovery; Compressor Heat Recovery

*Author for correspondence: m.aneke@hull.ac.uk, +447419983230

\section{Introduction}

Air separation unit (ASU) has become a process integral to many other processes mainly because of the importance of its constituents in many industrial applications. Prominent among them are nitrogen, oxygen and argon. Oxygen is used in medical and other industrial processes such as metals, glass, ammonia, oxy-fuel combustion and integrated gasification combined cycle (IGCC) for power generation (Burdyny and Struchtrup 2010; Jones et al. 2011; Liszka and Ziebik 2010; Zhu et al. 2008). Nitrogen is used in the chemical and petroleum industries (Vinson 2006) and currently is also considered as an energy carrier ( $\mathrm{Li}$ et al. 2010). Because of its inert nature, nitrogen has also been used in electronics and metal industries. Argon finds use as an inert shielding gas in welding, in growing silicon crystals as well as some other electronics like the light bulb. 
Air in its natural form is free and readily available, however, its separation into its components requires energy. The processes for air separation include: cryogenic distillation, pressure swing distillation, membrane separation (Rizk et al. 2012) and more recently, high temperature air separation (Rübberdt 2009). They are broadly grouped into cryogenic and non-cryogenic air separation with pressure swing distillation, membrane and high temperature separation under the non-cryogenic category.

Non-cryogenic ASU is mainly used in processes where very high purity products are not required. Typical purity for non-cryogenic (NC) oxygen and nitrogen systems are about 93 mol\% and 95 to $99.5 \mathrm{~mol} \%$ respectively (UIG, 2008), however, purities $>99.4$ mole \% oxygen and $>99 \mathrm{~mol} \%$ nitrogen have been reported in the literature for non-cryogenic ASU using a combination of oxygen permeable membrane and oxygen absorbent (Zhu et al. 2008). Apart from low purity, another setback suffered by non-cryogenic ASU is low product tonnage. This limits their application to processes where gas demand is relatively small (UIG, 2008). Although there are ongoing and promising advances in the non-cryogenic ASU systems, cryogenic ASU currently remains the status quo for industrial production of high purity tonnage quantities of oxygen and nitrogen (Fu and Truls 2012; Zhu et al. 2010).

Cryogenic ASU is a capital and energy intensive process. In a typical cryogenic ASU, the atmospheric air must be cleaned, compressed and cooled to about $-180{ }^{\circ} \mathrm{C}$, the liquefied stream is then distilled in large distillation tower in order to separate air into its components. The energy consumption of cryogenic ASU mainly comes from power requirement of the air feed compressor. The thermal energy required to regenerate molecular sieve used to remove unwanted components from the air $\left(\mathrm{H}_{2} \mathrm{O}, \mathrm{CO}_{2}\right.$, hydrocarbons etc.) prior to liquefaction contributes only about $10 \%$ of the energy requirement of the process (Pfaff and Kather 2009).

Different techniques have been proposed in order to reduce the capital and energy demand of cryogenic ASU. Amongst them are (a) the replacement of tray distillation columns with packed columns; (b) operating at higher pressure to reduce the overall column diameter; (c) improving the energy efficiency of heat exchangers and compressors and the use of control system with real-time optimization capability (Castle 2002; Kansha et al. 2011; Rübberdt 2009). Kansha et al. (2011) presented a novel self-heat recuperation cryogenic ASU and compared its performance with the conventional one. They found that their novel design reduced the overall energy consumption by more than 36\%. Manenti et al., (2013) found that pumping the liquid oxygen produced to a high pressure of 200 bar, vapourising the oxygen by exchanging heat with inlet air feed and generating power by expanding the oxygen vapour to the required pressure can help to lower the energy demand of a conventional process. Rizk et al., (2012) carried out a comparative exergy analysis between different distillation columns considered for cryogenic ASU and found that the exergy efficiency of a double diabatic column with heat transfer all through the length of the column is $23 \%$ higher than that of the conventional adiabatic double column. Fu and Gundersen (2012) carried out exergy analysis of cryogenic ASU for oxy-combustion processes and found that air compression and distillation system contributes about $38.4 \%$ and $28.2 \%$ of the exergy losses respectively. Van der Ham and Kjelstrup (2010) studied the thermodynamic performance of two cryogenic ASU configurations using exergy analysis. They found that the configuration with three distillation columns destroyed $12 \%$ less exergy than the two column design. They also found that half of the exergy is destroyed in the air compressor. In the same vein, Cornelissen and 
Hirs (1998) also carried out exergy analysis of cryogenic ASU process and found that onethird of the exergy is lost in the compression unit.

\subsection{Novel Contribution of this Study}

In conventional cryogenic ASU low grade heat is generated during the air compression operation. The generation of heat during the compression operation reduces the efficiency of the compressor. To maintain the efficiency of the compressors, the compressor needs to be cooled. The current industrial practice is to use water as the cooling medium for the compressor intercooler and after-cooler heat exchangers. As shown later in section 3 and Figures $2-5$, the use water as the cooling medium causes the extracted low grade heat not to be valuable to the process. However, replacing the cooling water loop with binary cycle heat engine results in the conversion of the compressor waste heat to electricity which is valuable to the process since it can be used to offset part of the electricity demand of the ASU. To the knowledge of the authors, there is no publication in the literature on the use of the low grade heat from air compressor of a cryogenic ASU for power generation using direct binary cycle heat engines (ORC systems) and that is the novelty which this paper tends to address.

\section{Description of a typical Conventional Cryogenic ASU}

The process flow diagram of a typical conventional cryogenic ASU is shown in Figure 1 (Kooijman, et al, 2006). The atmospheric air is filtered, cleaned and compressed in a 3 stage compressor with intercooling to a pressure of 6.35 bar. The compressed air is spilt into two, cooled and partially liquefied against the leaving product streams (gaseous nitrogen, liquid oxygen and gaseous waste product). One of the streams is sent to the first distillation column known as the high pressure column (HPC) where nitrogen is separated at a pressure of about 6 bar. The other stream is expanded to a pressure of about 1.2 bar and sent to the second distillation column known as the low pressure column (LPC). The top nitrogen product from the HPC is condensed against the boiling oxygen in the reboiler of the LPC, and depressurized before being sent to the top of the LPC. The bottom liquid product from the HPC which is rich in oxygen is also sent to the LPC after been depressurized using a JT valve. In the LPC, pure nitrogen vapour leaves from the top of the column, pure oxygen liquid leaves from the bottom. Two vapour side products are drawn from the LPC column. The side product towards the top is regarded as a waste product while the one towards the bottom of the column is sent to the side rectifier $(\mathrm{ArC})$ in order to separate Argon from Oxygen.

The process is a tight integration of heat exchangers and separation columns. The HPC and LPC share the same column shell to minimize the temperature difference between the condensing nitrogen and evaporating oxygen. The Joule-Thomson (JT) effect cools the rich liquid from the bottom of the HPC such that it can be used as the coolant to run the condenser of the side rectifier $(\mathrm{ArC})$ that separates argon from oxygen. Additional cooling was provided by using the JT effect in an expander which feeds compressed air directly to the LPC.

\section{Figure 1: Conventional Cryogenic ASU with 3 Stage Compressor}

\section{Heat Recovery Potential in a Conventional Cryogenic ASU using Binary Cycles}

From the literature, it can be seen that majority of the exergy loss occurs during air compression. The reason is because in a typical compression operation, about $90 \%$ of the electrical input is lost as heat. In the conventional cryogenic ASU under investigation in this 
work, the atmospheric air is compressed to a pressure of about 6.35 bar. This compression is usually achieved using multi-stage compressors (mainly 3 stage compressors, each with an average compression ratio of 1.95:1) with intercoolers which help to remove the heat from the compressor effluents. Intercooling also helps to improve the performance of the compressor by making the compressor to operate at near-isothermal condition. The temperature of air immediately after the $1^{\text {st }}, 2^{\text {nd }}$ and $3^{\text {rd }}$ stage compression is about $109^{\circ} \mathrm{C}$, $107{ }^{\circ} \mathrm{C}$ and $113{ }^{\circ} \mathrm{C}$ respectively. These air temperatures are required to be reduced to $40{ }^{\circ} \mathrm{C}$, $40{ }^{\circ} \mathrm{C}$ and $30{ }^{\circ} \mathrm{C}$ respectively using intercooler/after cooler heat exchangers. The intercooling is usually achieved using water at ambient condition. As shown in Figures 2 and 3, the use of water as the cooling medium limits the use of the extracted heat to only heat integration because the exit water temperature from the intercooler will not be useful for any other waste heat recovery application such as direct Rankine cycle application. This may not be beneficial in a standalone cryogenic ASU because such heat may not be needed anywhere else in the plant.

Figure 2: Intercooler Outlet Water Condition for 3 stage compressor (cooling water source temperature and pressure $20^{\circ} \mathrm{C}$ and 1 bar)

Figure 3: Intercooler Outlet Water Condition for 3 stage compressor (cooling water source temperature and pressure $20{ }^{\circ} \mathrm{C}$ and 200 bar)

Alternatively, the recent advancement in compressor design makes it possible to have a single stage compressor capable of achieving a compression ratio of $10-12: 1$ (Baldwin 2009). The use of such compressor to replace the 3 stage compressor will give rise to higher air temperature at the compressor outlet. For example, it was found that replacing the 3 stage compressor with a single stage compressor at the same overall pressure ratio produces compressed air at $287.2{ }^{\circ} \mathrm{C}$. Figures 4 and 5 show that even with the high air temperature obtained at the compressor exit, using water as the cooling medium will also limit the extracted heat to only heat integration application which might not be beneficial to the process.

Figure 4: After cooler outlet water condition for 1 stage compressor (cooling water source temperature and pressure $20^{\circ} \mathrm{C}$ and 1 bar)

Figure 5: After cooler outlet water condition for 1 stage compressor (cooling water source temperature and pressure $20{ }^{\circ} \mathrm{C}$ and 200 bar)

Hence, since the extracted compressor heat may not be used anywhere else in the process, the conversion of the heat to electricity using ORC system will be of utmost benefit to the process.

Thermal energy recovery has been identified as a useful means to reduce energy wastage, increase resource savings, improve the energy efficiency of processes as well as reduce the environmental impact of heat pollution and global warming (Aneke et al. 2012b). The use of 
binary cycles otherwise known as ORC systems for waste heat recovery is a technologically matured process. The technology has been implemented in many processes in both commercial and pilot scale for the recovery of waste heat. Prominent among them are the oil and gas (Alford 2005; Mettler 2006; Nasir et al. 2004), cement manufacturing (Legmann and Citrin 2004), geothermal power generation (Aneke et al. 2011; Brasz et al. 2005; Holdmann 2007a; b), solar power generation (García-Rodríguez and Blanco-Gálvez 2007; Lozanova 2009; Wang and Zhao 2009), food manufacturing(Aneke et al. 2012a; Aneke et al. 2012b) and ship and gas turbine exhaust heat recovery(Siemens-AG 2009; Yari and Mahmoudi 2011; Yari and Mahmoudi 2010).

The highest heat recovery potential in a conventional cryogenic ASU lies in the compression operation since one-third of the exergy in the process is lost during the compression. The application of heat recovery using ORC system in a cryogenic ASU will provide a combined compressor and heat recovery system which will create impressive energy efficiency by recovering about $90-98 \%$ of the compressor electrical energy input in the form of heat energy which can be used for power generation. This can be achieved by replacing the cooling water with the ORC working fluid.

In this paper we will investigate the energy efficiency improvement potential in a cryogenic ASU by using either a single stage or multiple stage (3 stages) air compressor system combined with heat recovery from the compressor discharge using ORC system for power generation as against the conventional system which uses water as the cooling medium.

\subsection{Simulation of Different Configurations of Compressor Heat Recovery in cryogenic ASU using ORC System.}

Two different combined compressor and heat recovery arrangements were modeled and simulated in order to compare their performance against a conventional cryogenic ASU. One of the arrangements is similar to the conventional cryogenic ASU except that the water used for intercooling is replaced with R134a which serves as both the coolant and the ORC working fluid. In the second arrangement, the 3 stage compressor is replaced with a single stage compressor of the same overall pressure ratio while the after cooling is achieved using R134a which also serves as the working fluid for the ORC system. The details of each of the configurations are explained in sections 3.1.1 and 3.1.2. The simulations were carried out in Aspen Plus ${ }^{\circledR}$ simulation software v. 8.1 using Peng Robinson equation of state to calculate the physical properties. The process parameters used to develop the models of the cryogenic ASU were obtained from Kooijman, et al, (2006). The parameters used to model the cryogenic ASU as well as the ORC system are shown in Table 1.

\subsubsection{Cryogenic Air Separation with 3 Stage Compression and Waste Heat Recovery from Intercooler/After cooler using ORC System (C3WHR)}

This scenario is based on the conventional cryogenic ASU system. The only difference is the replacement of the cooling water used for the interstage and after cooling with R134a. Figure 6 shows the process flow diagram of the arrangement. Similar to the conventional cryogenic process, the exit temperature of the air immediately after the $1^{\text {st }}, 2^{\text {nd }}$ and $3^{\text {rd }}$ stage compression is $109{ }^{\circ} \mathrm{C}, 107{ }^{\circ} \mathrm{C}$ and $113{ }^{\circ} \mathrm{C}$ respectively. They are cooled to $40{ }^{\circ} \mathrm{C}, 40{ }^{\circ} \mathrm{C}$ and $30{ }^{\circ} \mathrm{C}$ at the intercooler and after cooler heat exchangers using R134a which also serves as the working fluid for the heat recovery ORC system. 
Table 1: Process Parameters

Figure 6: Cryogenic ASU with 3 Stage Compressor and Waste Heat Recovery using ORC System

\subsubsection{Cryogenic Air Separation with Single Stage Compression and Waste Heat Recovery using ORC (CIWHR)}

In this scenario, the conventional 3 stage compressor is replaced with a single stage compressor with the same overall pressure ratio. The use a single stage compressor increased the air temperature at the compressor exit to $287.2{ }^{\circ} \mathrm{C}$ which has to be cooled down to $30{ }^{\circ} \mathrm{C}$ using R134a which also doubles as the working fluid for the ORC system. When compared with the previous scenario, this translates into higher heat recovery as well as higher power generation from the ORC system, however, this is at the expense of higher power consumption by the compressor which operates strictly adiabatic unlike the 3 stage scenario which operates at near-isothermal condition due to the interstage cooling. The process flow diagram of this arrangement is shown in Figure 7.

\section{Figure 7: Cryogenic ASU with Single Stage Compressor and Waste Heat Recovery using ORC System}

The performance parameter for all the arrangements were calculated using the following formula:

The specific power consumption for producing any given pure product is defined as:

$$
\beta_{\text {sp }}=\sum\left(\mathrm{P}_{\text {in }}-\mathrm{P}_{\text {out }}\right) / \mathrm{m}
$$

where,

$\sum \mathrm{P}_{\text {in }}=$ sum of the power inputs to the process $(\mathrm{kW}), \sum \mathrm{P}_{\text {out }}=$ sum of the power outputs from the process $(\mathrm{kW}), \mathrm{m}=$ mass of the pure product, $(\mathrm{kg} / \mathrm{h})$

The overall specific power consumption for producing pure products is calculated as:

$$
\beta_{\text {ov }}=\sum\left(\mathrm{P}_{\text {in }}-\mathrm{P}_{\text {out }}\right) / \sum m
$$

where, 
$\sum \mathrm{P}_{\text {in }}=$ sum of the power inputs to the process $(\mathrm{kW}), \sum \mathrm{P}_{\text {out }}=$ sum of the power outputs from the process $(\mathrm{kW}), \sum \mathrm{m}=$ sum of the mass of the pure product $(\mathrm{kg} / \mathrm{h})$

The combined compressor and waste heat recovery electric efficiency is calculated as:

$$
\eta_{\mathrm{eff}}=\left(\mathrm{P}_{\mathrm{G}}-P_{P}\right) / \mathrm{P}_{\mathrm{C}}
$$

where,

$\mathrm{P}_{\mathrm{G}}=$ Power output of the ORC system generator $(\mathrm{kW}), \mathrm{P}_{\mathrm{P}}=$ ORC system pump power consumption $(\mathrm{kW}), \mathrm{P}_{\mathrm{C}}=$ Compressor power input $(\mathrm{kW})$

The thermal efficiency of the ORC system is calculated as:

$$
\mu_{\mathrm{eff}}=\mathrm{P}_{\mathrm{G}}-P_{P} / \sum Q_{\text {in }}
$$

where,

$\mathrm{P}_{\mathrm{G}}=$ Power output of the ORC system process, $(\mathrm{kW}), \mathrm{P}_{\mathrm{P}}=$ ORC system pump power consumption, $(\mathrm{kW}), \sum$ Qin $=$ Total heat recovery from the intercooler/after cooler heat exchanger $(\mathrm{kW})$

\section{Results and Discussion}

Table 2 shows the simulation results of the three different CASU configurations modelled in this paper.

\section{Table 2: Table of Simulation Results}

The results of the two different CASU with heat recovery using ORC system were compared against the conventional CASU which was used as the benchmark. The simulation results show that all the CASU scenarios met the tight heat integration specification required of a conventional CASU process. The nitrogen produced in the HPC was condensed at $-177.57^{\circ} \mathrm{C}$ against the boiling oxygen at $-180.33{ }^{\circ} \mathrm{C}$ from the bottom of the LPC. Similarly, the argon produced in the argon separation column was condensed at $-184.90{ }^{\circ} \mathrm{C}$ against the JT effect of the oxygen rich product from the bottom of the HPC which is at $-191.10^{\circ} \mathrm{C}$.

For a conventional CASU which processes $360 \times 10^{3} \mathrm{~kg} / \mathrm{h}$ of ambient air $\left(1 \mathrm{~atm}\right.$ and $\left.30{ }^{\circ} \mathrm{C}\right)$, the compression power was found to be $22273.54 \mathrm{~kW}$ with specific power consumption for the individual pure products of oxygen (99.90 mole \%), nitrogen (99.99 mole \%) and argon (97.00 mole \%) of $0.357 \mathrm{kWh} / \mathrm{kg}, 0.421 \mathrm{kWh} / \mathrm{kg}$ and $19.558 \mathrm{kWh} / \mathrm{kg}$ respectively. As expected, the replacement of the 3 stage water cooled compression arrangement in the conventional CASU with a single stage compressor (C1WHR) with the same overall compression ratio causes the discharged air temperature to rise to $287^{\circ} \mathrm{C}$. This increase in the discharge air temperature results in the generation of $3866.36 \mathrm{~kW}$ of net electricity from the binary cycle heat engine (ORC) system which is used as both the compressor cooling medium and for converting the extracted compressor low grade heat to electricity. Due to the generation of power using the low grade heat from the compressor effluent, the specific power consumption for the individual pure products was found to be $0.356 \mathrm{kWh} / \mathrm{kg}, 0.420$ 
$\mathrm{kWh} / \mathrm{kg}$ and $19.533 \mathrm{kWh} / \mathrm{kg}$ for oxygen, nitrogen and argon respectively. These values were better than that of the conventional 3 stage CASU which uses water as the cooling medium however; the improvement in efficiency which occurs as a result of the replacement of the water cooler with the ORC system is very small. The reason is because for the same compression ratio, the compressor of the single stage compression arrangement (C1WHR) behaves adiabatically and thus consumes more electricity than the conventional water cooled 3 -stage compressor which behaves nearly isothermally. Thus, despite the use of the ORC to generate electricity from the single stage compressor low grade heat, it was found that the net electricity generated from the ORC system is slightly higher than the extra electricity consumed by the adiabatic single stage compressor used to replace the near isothermal 3 stage water cooled compressor. For example, for the same overall compression ratio, the single stage compressor uses $26226.50 \mathrm{~kW}$ of electricity compared to the $22273.54 \mathrm{~kW}$ consumed by the 3 stage water cooled arrangement used in the conventional cryogenic ASU. The net power of $3866.36 \mathrm{~kW}$ generated from the ORC system of the C1WHR process is slightly lower than $3952.96 \mathrm{~kW}$ which is the extra power consumed in the single stage adiabatic compressor when compared with the 3 stage water cooled arrangement in the conventional process. In other words, for the same compressor ratio investigated in this work, the replacement of the 3 stage water cooled compressor of the conventional CASU with a single stage ORC cooled compressor arrangement only results in a slight increase in energy efficiency due to the extra power consumed in the adiabatic single stage compressor.

On the other hand, the replacement of the water cooling medium of the intercooler/after cooler arrangement of the 3 stage compressor of the conventional CASU process with ORC system using R134a working fluid while retaining the 3 stage compression arrangement (C3WHR) provides a better overall energy efficiency as shown by the specific power consumption values of $0.316 \mathrm{kWh} / \mathrm{kg}, 0.373 \mathrm{kWh} / \mathrm{kg}$ and $17.346 \mathrm{kWh} / \mathrm{kg}$ respectively for the pure oxygen, nitrogen and argon. The reason is because the C3WHR system combines the advantages of the near-isothermal compression (as a result of intercooling) which reduces the compressor electricity demand and the generation of extra electricity by the ORC system using the compressor low grade heat. The significant reduction in the compressor electricity consumption due to near isothermal operation together with the extra electricity generated via the ORC system causes the C3WHR process to be more energy efficient than both the C1WHR process and the conventional 3 stage water cooled CASU. Compared to the conventional 3 stage water cooled process, the C3WHR was found to reduce the overall net process power consumption by $11 \%$ while the C1WHR achieves only $0.13 \%$ reduction.

\section{Conclusions}

The utilisation of the low grade heat from the compressor of a cryogenic ASU for power generation is technologically viable and can significantly improve the energy efficiency of the process by reducing its specific power consumption as well as overall net power consumption; however, the level of improvement depends significantly on the mode of operation of the compressor. Within the design constraint imposed in the ORC systems modelled in this work and used for the recovery of low grade heat from compressor effluents, it was found that a single stage compressor with waste heat recovery arrangement produces a high temperature effluent stream from the compressor which translates into high power generation by the ORC system. However, the extra power consumed in the single stage adiabatic compressor makes the overall specific power consumption of the process to be 
slightly better than the conventional water cooled CASU. A more efficient process is obtained by combining a multistage compression with waste heat recovery using ORC system. The multistage stage system allows the compressor to operate at near-isothermal condition while the ORC system helps to convert the low grade heat from the compressor effluent to electricity.

Thus, since the number of compression stages depends on the pressure ratio and the required overall process pressure to be achieved, it is pertinent to note that the optimum pressure ratio is that which will give an optimum intercooling condition for waste heat recovery using ORC system as well as cause the compression arrangement to operate at near-isothermal condition.

\section{References}

Alford, J. (2005). "Cajun Converter, Don't Ya Know." Progressive Engineer.

Aneke, M., Agnew, B., and Underwood, C. (2011). "Performance analysis of the Chena binary geothermal power plant." Applied Thermal Engineering, 31(10), 1825-1832.

Aneke, M., Agnew, B., Underwood, C., and Menkiti, M. (2012a). "Thermodynamic Analysis of Alternative Refrigeration Cycles Driven from Waste Heat in a Food Processing Application." International Journal of Refrigeration(35), 1349 - 1358.

Aneke, M., Agnew, B., Underwood, C., Wu, H., and Masheiti, S. (2012b). "Power Generation from Waste Heat in a Food Processing Application." Applied Thermal Engineering, 36(2012), 171-180.

Baldwin, P. (2009). "CO ${ }_{2}$ Compressors Special Edition." Carbon Capture, Sept/Oct 2009(11), $19-21$.

Brasz, J. J., Biederman, B. P., and Holdmann, G. (2005). "Power production from a moderate-temperature geothermal resources." In: GRC Annual Meeting, Reno, USA.

Burdyny, T., and Struchtrup, H. (2010). "Hybrid membrane/cryogenic separation of oxygen from air for use in the oxy-fuel process." Energy, 35(2010), 1884 - 1897.

Castle, W. F. (2002). "Air separation and liquefaction: recent developments and prospects for the beginning of the new millennium." International Journal of Refrigeration, 25(2002), $158-172$.

Cornelissen, R. L., and Hirs, G. G. (1998). "Exergy Analysis of Cryogenic Air Separation." Energy Convers. Mgmt, 29(16), 1821 - 1826.

$\mathrm{Fu}, \mathrm{C}$., and Truls, G. (2012). "Using exergy analysis to reduce power consumption in air separation units for oxy-combustion processes." Energy, 44(2012), 60 - 68.

García-Rodríguez, L., and Blanco-Gálvez, J. (2007). "Solar-heated Rankine cycles for water and electricity production: POWERSOL project." Desalination, 212(1-3), 311-318.

Holdmann, G. (2007a). "400kW Geothermal Power Plant at Chena Hot Springs, Alaska." In: Final Project Report Prepared for the Alaska Energy Authority, Chena Power Company, Alaska, 1-37.

Holdmann, G. (2007b). "The Chena Hot Springs 400kW Geothermal Power Plant: Experience Gained During the First Year of Operation." In: Chena Geothermal Power Plant Report, Chena Power Plant, Alaska, 1-9.

Jones, D., Bhattacharyya, D., Turton, R., and Zitney, S. E. (2011). "Optimal design and integration of an air separation unit (ASU) for an integrated gasification combined cycle (IGCC) powe plant with $\mathrm{CO}_{2}$ capture." Fuel Processing Technology, 92(2011), $1585-1595$.

Kansha, Y., Kishimoto, A., Nakagawa, T., and Tsutsumi, A. (2011). "A novel cryogenic air separation process based on self-heat recuperation." Separation and Purification Technology, 77(2011), 389 - 396. 
Kooijman, H., Taylor, R., and van Baten, J. (2006). "The ChemSep/COCO Casebook: Air Separtion Unit".

Legmann, H., and Citrin, D. (2004). "Low Grade Heat Recovery." ORMAT International, Inc, USA.

Li, Y., Chen, H., Zhang, X., Tan, C., and Ding, Y. (2010). "Renewable energy carriers: Hydrogen or liquid air/nitrogen?" Applied Thermal Engineering, 30(2010), 1985 1990.

Liszka, M., and Ziębik, A. (2010). "Coal-fired oxy-fuel power unit - Process and system analysis." Energy, 35(2010), 943 - 951.

Lozanova, S. (2009). "How to make electricity from wasted energy." In: Clean Technica, www.cleantechnica.com.

Manenti, F., Rossi, F., Croce, G., Grottoli, M. G., and Altavilla, M. (2013). "Intensifying Air Separation Units." Chemical engineering Transactions, 35(2013).

Mettler, D. (2006). "Recycling Heat Energy into Electricity." ORMAT Inc, USA.

Nasir, P., Jones, S., Buchanan, T., and Posner, D. (2004). "Turning Recovered Heat to Power." In: Hart Pipeline and Gas Technology: A Hart Energy Publication, Hart Energy Publishing, Houston, Texas, USA.

Pfaff, I., and Kather, A. (2009). "Comparative Thermodyanmic Analysis and Integration Issues of CCS Steam Power Plants Based on Oxy-Combustion with Cryogenic or Membrane Based Air Separation." Energy Procedia, 1(2009), 495 - 502.

Rizk, J., Nemer, M., and Clodic, D. (2012). "A real column design exergy optimization of a cryogenic air separation unit." Energy, 37(2012), 417 - 429.

Rübberdt, K. (Year). "Producing oxygen and nitrogen: Air separation techniques continue to advance." ACHEMA 2009, 29th International Exhibition Congress in Chemical Engineering, Environmental Protection and Biotechnology, Frankfurt am Main, Germany.

Siemens-AG. (2009). "Siemens delivers booster propulsions and waste heat recovery energy management systems for United Arab Shipping Company's nine new-building container ships."www.siemens.com/press/en/pressrelease (20 March, 2010).

UIG (2008). Universal Industrial Gases, Inc., "Non-Cryogenic Air Separation Processes". www.uigi.com.

van der Ham, L. V., and Kjelstrup, S. (2010). "Exergy analysis of two cryogenic air separation processes." Energy, 35(2010), 4731 - 4739.

Vinson, D. (2006). "Air separation control technology." Computers \& Chemical Engineering, 30(2006), 1436 - 1446.

Wang, X. D., and Zhao, L. (2009). "Analysis of zeotropic mixtures used in low-temperature solar Rankine cycles for power generation." Solar Energy, 83(5), 605-613.

Yari, M., and Mahmoudi, S. M. (2011). "A thermodynamic study of waste heat recovery from GT-MHR using organic Rankine cycles (ORCs)." Heat and Mass Transfer, 47(2), 181-196.

Yari, M., and Mahmoudi, S. M. S. (2010). "Utilization of waste heat from GT-MHR for power generation in organic Rankine cycles." Applied Thermal Engineering, 30(4), 366-375.

Zhu, X., Sun, S., He, Y., Cong, Y., and Yang, W. (2008). "New concept on air separation." Journal of Membrane Science, 323(2008), 221 - 224.

Zhu, Y., Legg, S., and Laird, C. D. (2010). "Optimal design of cryogenic air separation columns under uncertainty." Computers \& Chemical Engineering, 34(2010), 1377 1384 . 
Tables

Table 1

\begin{tabular}{|l|l|}
\hline \multicolumn{2}{|c|}{ Cryogenic ASU } \\
\hline Parameter & Value \\
\hline Inlet Air mass flowrate & $100 \mathrm{~kg} / \mathrm{s}$ \\
\hline Inlet Air molar composition & \\
Nitrogen & 0.7812 \\
Oxygen & 0.2095 \\
Argon & 0.0093 \\
\hline Air inlet temperature & $30{ }^{\circ} \mathrm{C}$ \\
\hline Compressor stage outlet pressures & \\
Stage 1 & $1.98 \mathrm{bar}$ \\
Stage 2 & $3.46 \mathrm{bar}$ \\
Stage 3 & $6.35 \mathrm{bar}$ \\
\hline Compressor Isentropic efficiency & \\
Stage 1 & $80 \%$ \\
Stage 2 & $80 \%$ \\
Stage 3 & $80 \%$ \\
\hline Compressor single stage efficiency & $80 \%$ \\
\hline Intercooler/ after cooler Air Outlet temperature & \\
Intercooler 1 & $40{ }^{\circ} \mathrm{C}$ \\
Intercooler 2 & $40{ }^{\circ} \mathrm{C}$ \\
After cooler & $30{ }^{\circ} \mathrm{C}$ \\
\hline Low Pressure Column Pressure (LPC) & $1.2 \mathrm{bar}$ \\
\hline Low Pressure Column no of stages & 45 \\
\hline High Pressure Column Pressure (HPC) & $6 \mathrm{bar}$ \\
\hline High Pressure Column no of stages & 69 \\
\hline Argon Column Pressure & $1.2 \mathrm{bar}$ \\
\hline Argon Column number of stages & 120 \\
\hline Expander isentropic efficiency & $80 \%$ \\
\hline & $80 \%$ \\
\hline Expander isentropic efficiency & $80 \%$ \\
\hline Pump efficiency & \\
\hline
\end{tabular}


Table 2

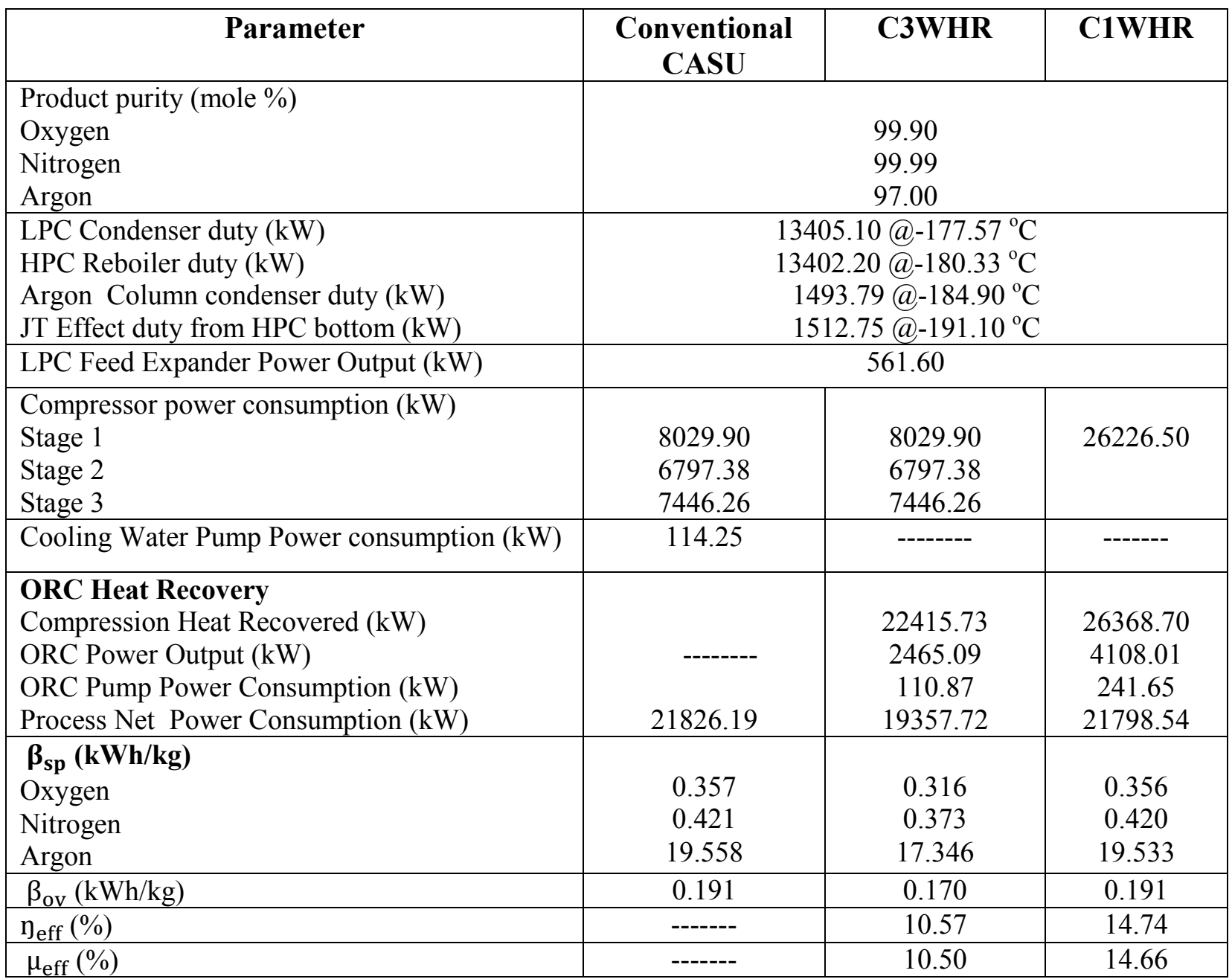




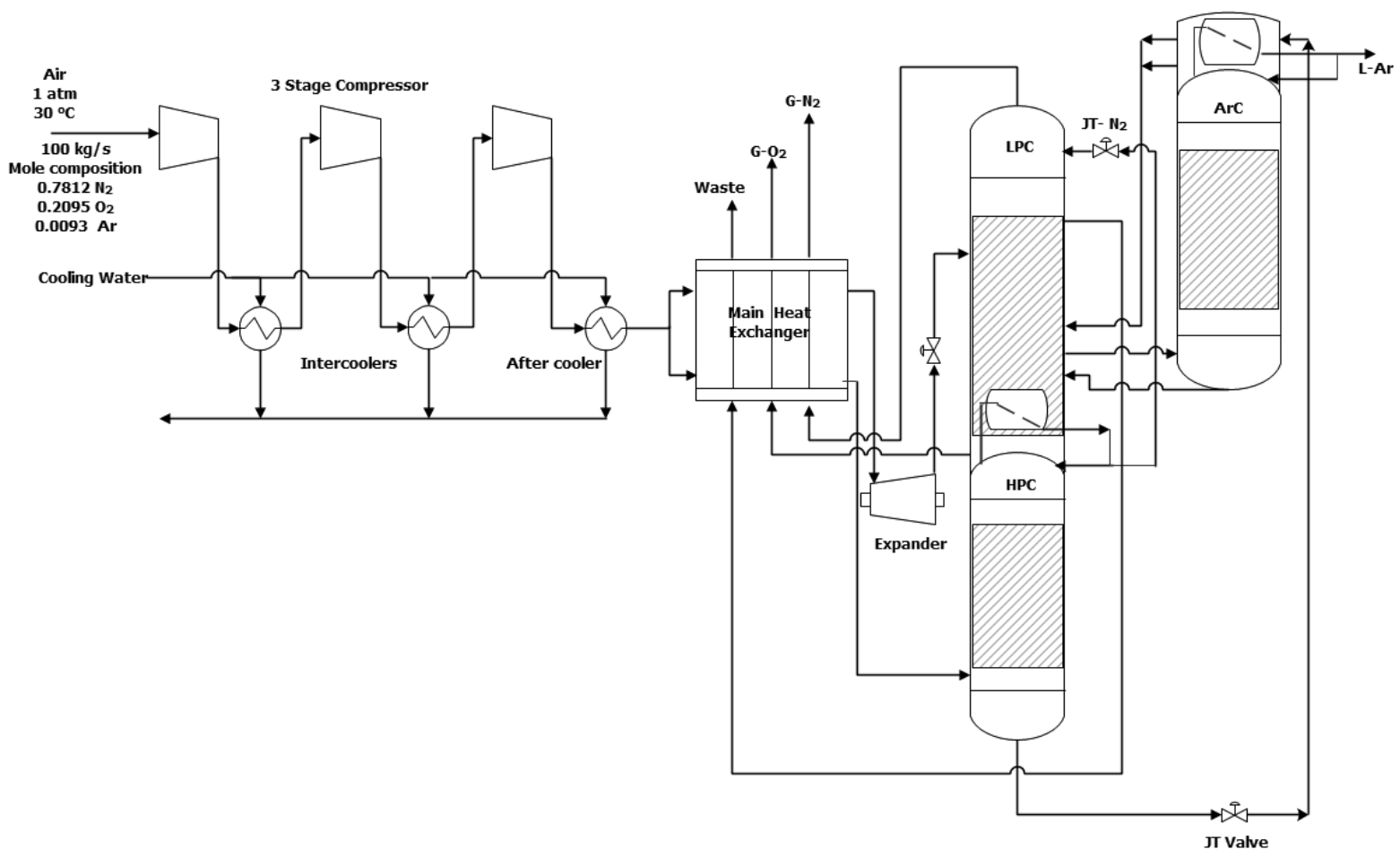

Figure 1: Conventional Cryogenic ASU with 3 Stage Compressor

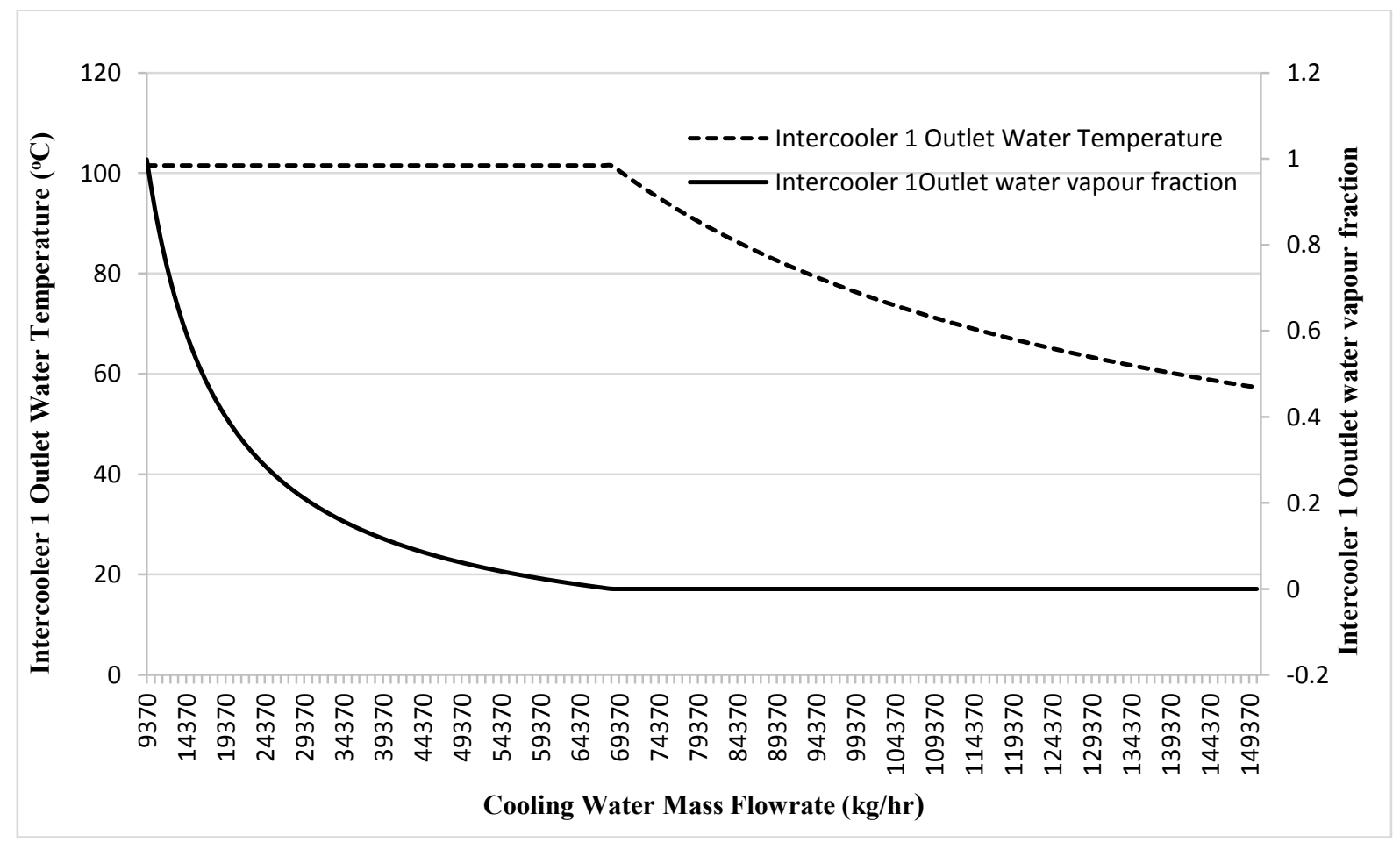

Figure 2: Intercooler Outlet Water Condition (cooling water source temperature and pressure $20^{\circ} \mathrm{C}$ and 1 bar) 


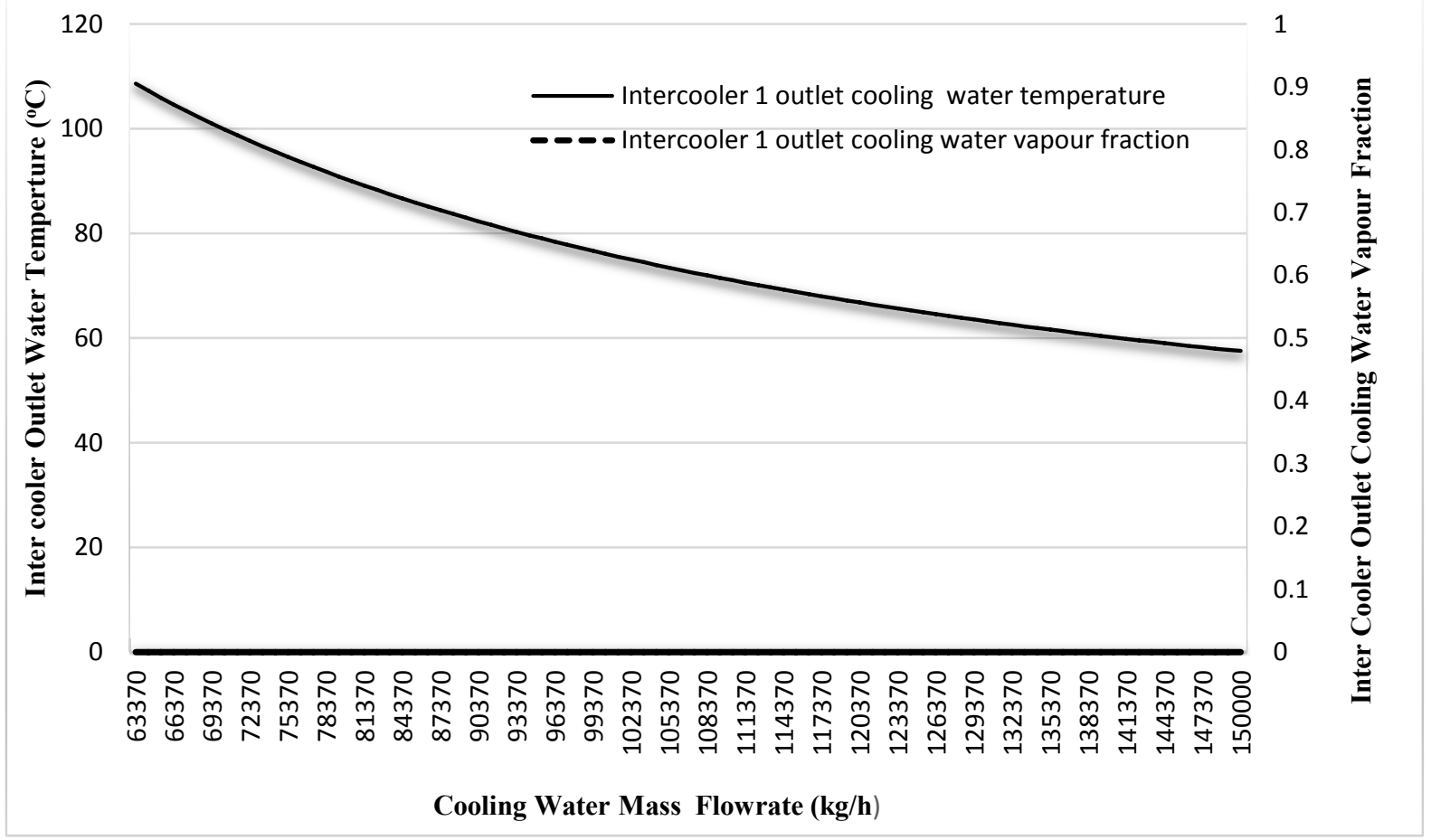

Figure 3: Intercooler Outlet Water Condition (cooling water source temperature and pressure $20{ }^{\circ} \mathrm{C}$ and 200 bar)

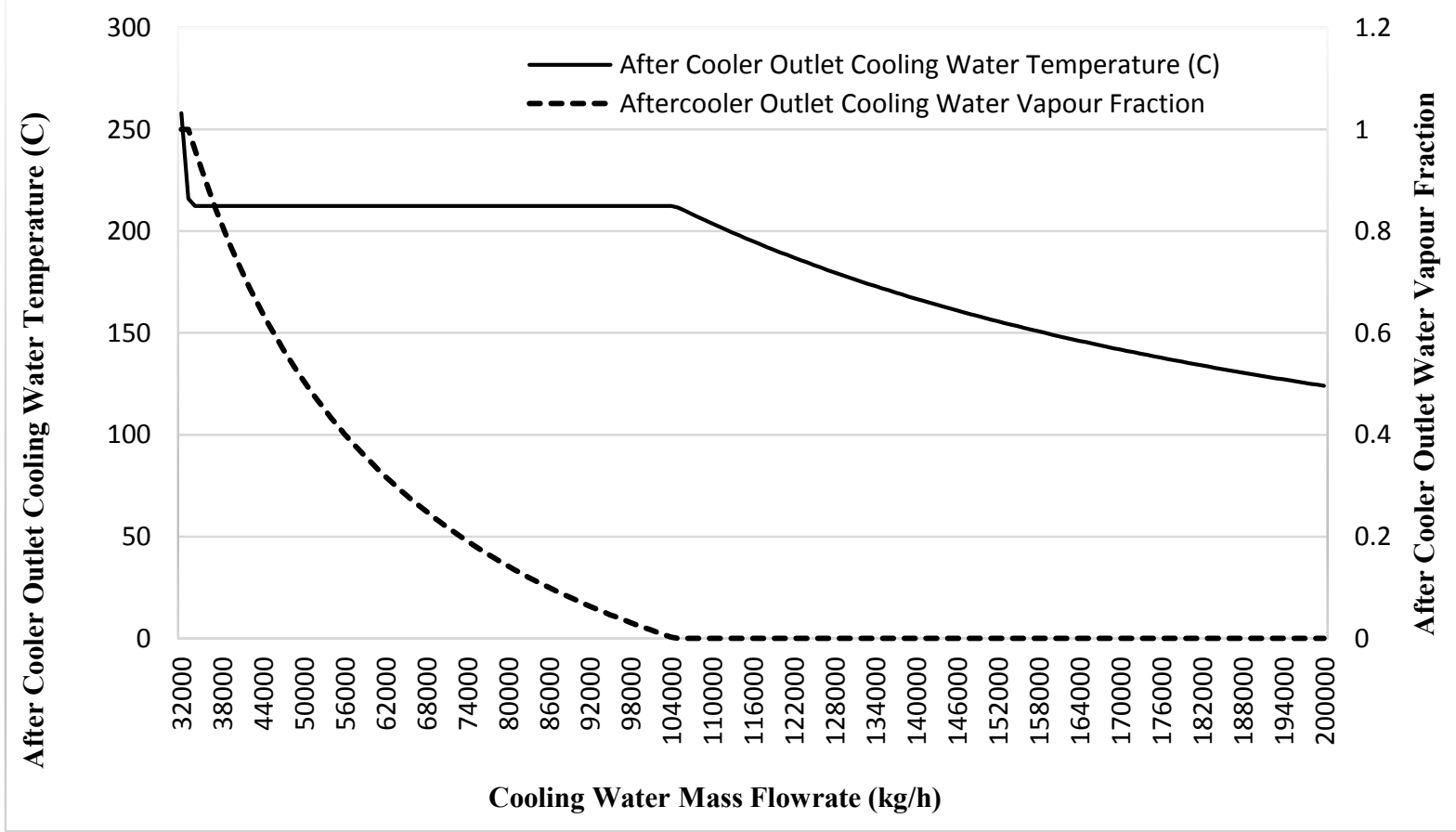

Figure 4: After cooler outlet water condition for 1 stage compressor (cooling water source temperature and pressure $20^{\circ} \mathrm{C}$ and 1 bar) 


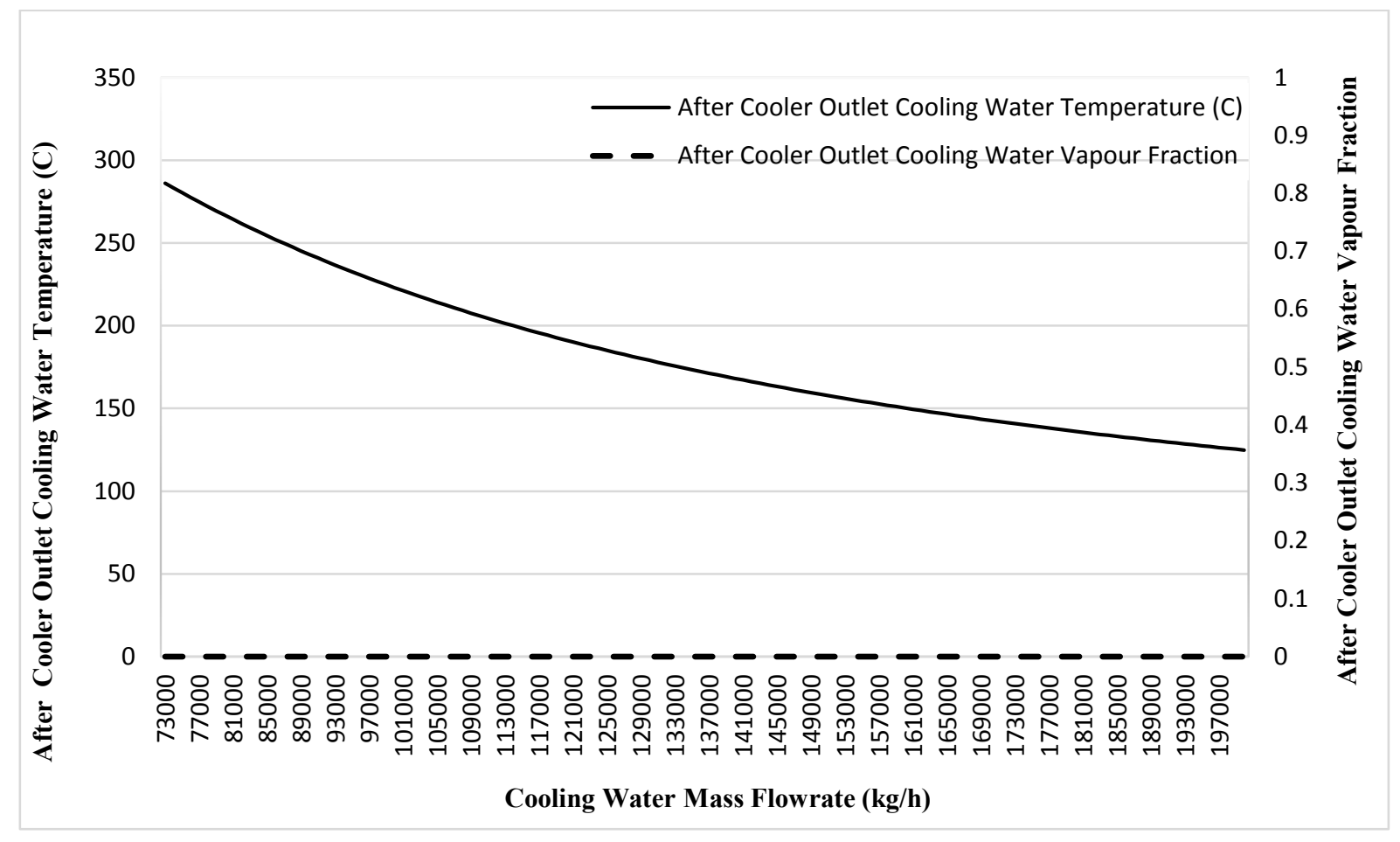

Figure 5: After cooler outlet water condition for 1 stage compressor (cooling water source temperature and pressure $20^{\circ} \mathrm{C}$ and 200 bar) 


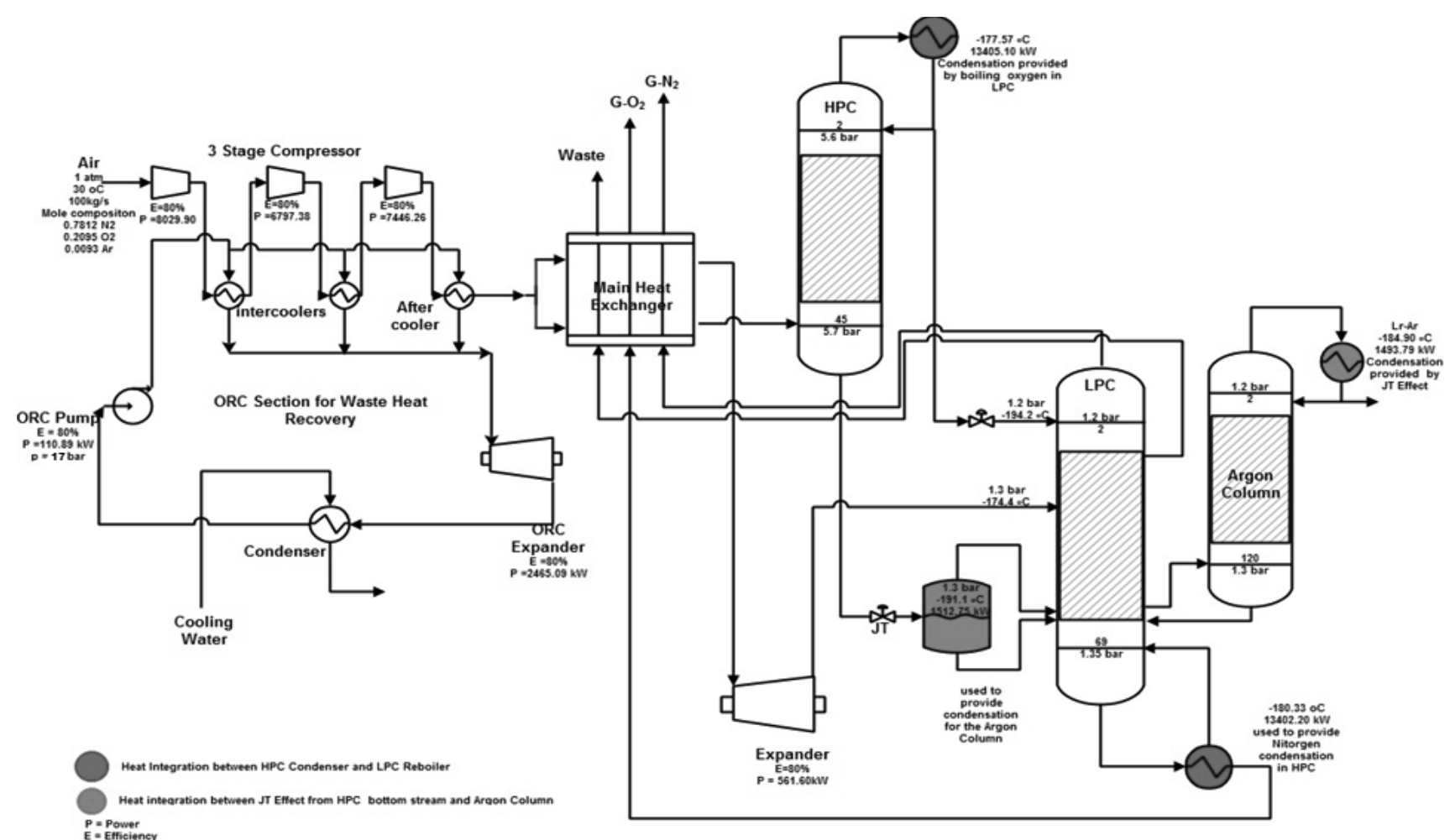

Figure 6: Cryogenic ASU with 3 Stage Compressor and Waste Heat Recovery using ORC System 


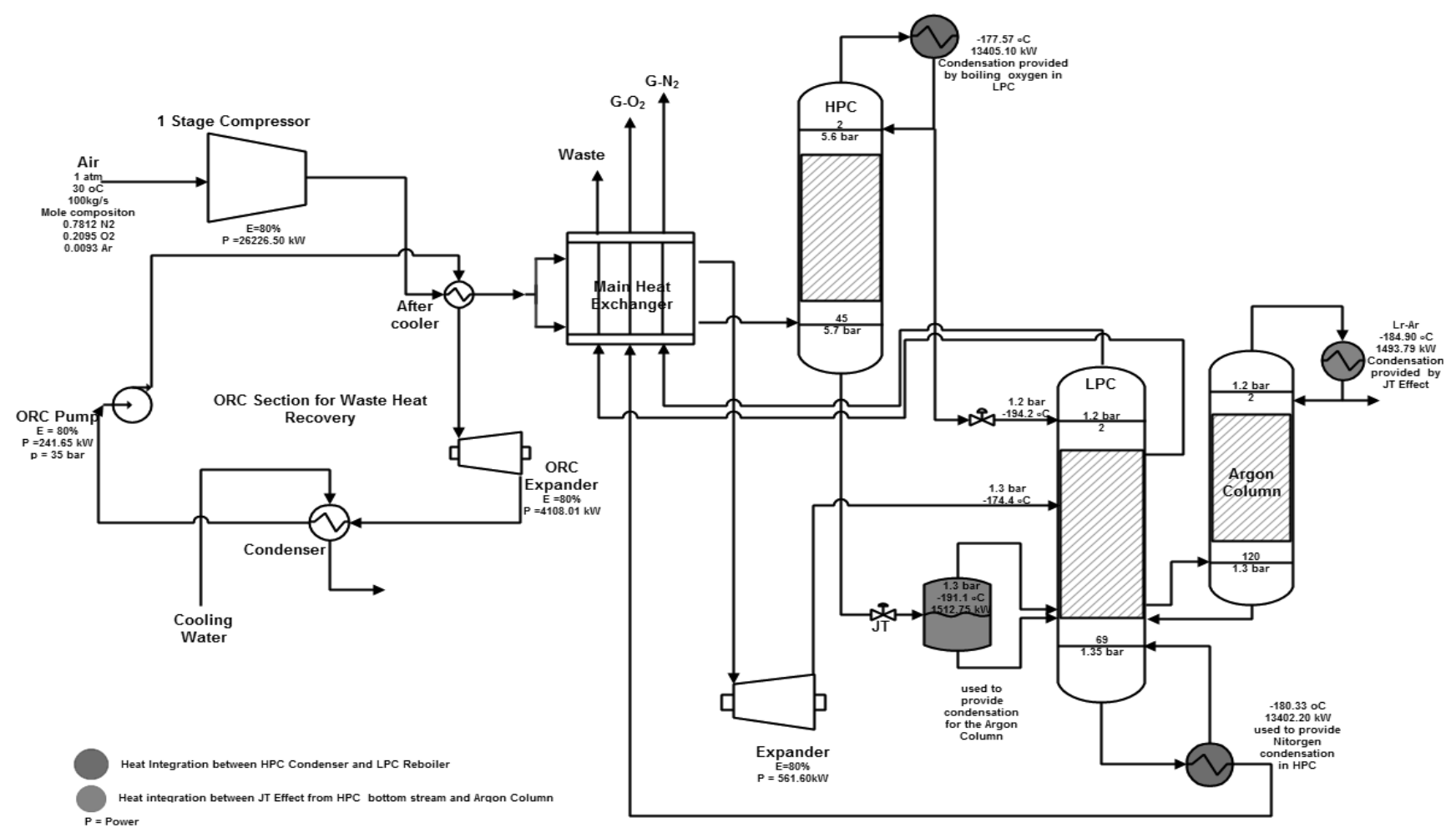

Figure 7: Cryogenic ASU with Single Stage Compressor and Waste Heat Recovery using ORC System 